\title{
QUALITY RISK MANAGEMENT IN \\ PHARMACEUTICAL INDUSTRIES
}

\author{
Abdul Sattar Khan, Fauziya Khan and Nutan Rao* \\ Oriental Collegeof Pharmacy, Sanpada, \\ Navi Mumbai, Mumbai University, Maharashtra, India.
}

\begin{abstract}
Current review explains the principles and examples of tools for Quality Risk Management (QRM) that can be applied to different aspects of pharmaceutical quality. Quality and attributes of pharmaceutical product is an important parameter throughout lifecycle owing to its importance as acceptance criteria at customer's end. Drugs regulatory agencies have issued guidelines (ICH Guideline) for quality risk evaluation, mitigation and review management. The Quality risk management has become an important and integral part of quality management system at manufacturing plants. These are somerelatedmethods for change control, deviation control, investigations of market complaints and batch failures and are dealt with the principle of quality risk management at the manufacturing facility. These are afew of the parameters which consist of manufacturing, distribution, product development, inspection and submission of reviewprocesses during the lifecycle of drug substances, drug products and biological products.
\end{abstract}

Keywords: Quality Risk Management, Risk- based approach, Patient safety and Product quality.

\section{INTRODUCTION \\ Quality}

The degree to which a set of fundamental properties of a product, system, or process fulfills requirements.

\section{Quality risk management}

A systematic process for the control, communication, assessment, and review of risks to the quality of the drug product throughout the product lifecycle.

\section{Risk}

The combination of the probability of occurrence of harm and the severity of that harm where the source of the harm is a biological agent or toxin (ISO/IEC Guide 51).

Product quality should be maintained across the product lifecycle. In the earlier days, risk was assessed in the following ways ${ }^{1}$

$\checkmark$ Trends review

$\checkmark$ Check lists

$\checkmark$ Flow charts

$\checkmark$ Observations compilation

\section{$\checkmark$ Changes review}

Howevernow the risk management approach initiated by regulatory agencies with accepted management tools, along with support of statistical tools are implemented across the industry.

Since a couple of years Quality Risk Management (QRM) has become a mandatory regulatory requirement towards healthcare organizations. The QRM is complete and continuing process of minimizing risks to product quality during its life-cycle in order to optimize its benefit and balance the risk. These are systematic process for the evaluation, control, communication and review of risks to the quality of the medicinal product. They must support science based and practical decisions whencombined into quality system, Examples of quality system include Validation, Quality Defect - Investigation, Auditing, Documentation, Analysis, Training etc. Quality Risk Management rules are adequately used in many areas including insurance, business, work associated safety, 
public health, pharmacovigilance, and by agencies regulating these industries ${ }^{2}$.

\section{Scope ${ }^{3}$}

It provides the principles and examples of tools for quality risk management that can be applied to different aspects of pharmaceutical quality.

These aspects include
a) Development
b) Manufacturing
c) Distribution
d) Inspection
e) The submission or review processes throughout the lifecycle of drug substances, drug products, biological and biotechnological products.

\section{They also include the use of}

a) Raw materials

b) Solvents

c) Excipients

d) The packaging and labelling materials in drug products, biological and biotechnological products.
Principles of quality risk management ${ }^{4}$

The four basic primary principles of QRM are

a) The assessment of risk to quality should be based on scientific knowledge and ultimately link to the protection of the patient.

b) QRM should be dynamic, iterative and responsive to change.

c) The level of effort zone, formality and documentation of the QRM process should be commensurate with the level of risk.

d) The capability of continual development and enhancement should be embedded in the QRM process.

\section{General quality risk management process}

The process of Quality risk management is a systematic process for the appraisal, control and prevention and review of risk to the quality ofthedrugproduct across the product life cycle. Overview of a typical quality risk management process is shown in Figure 1.

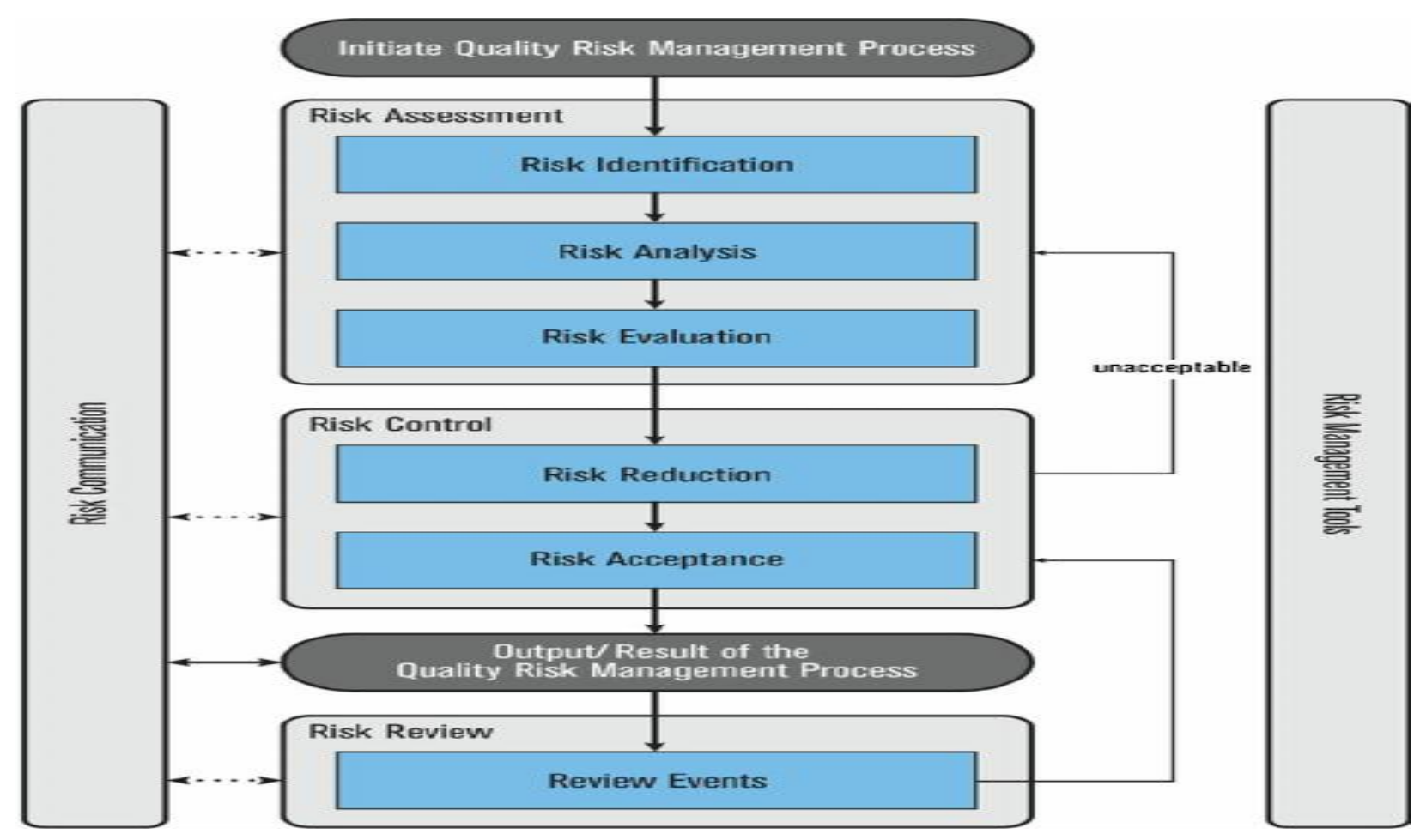

Fig. 1: Overview of a typical quality risk management process

Note: "The unacceptable part" in the flow chart does not only refer to legislative, statutory or regulatory requirements, but also to indicate that risk assessment process should be revisited

i. Responsibilities ${ }^{5,6}$

The Quality risk management activities are usually, but not always, undertaken by interdisciplinary teams 
Decision makers should be able:

a. To take the responsibility for coordinating quality risk management across various functions and departments of their organization and

b. To Ensure that a quality risk management process is defined, deployed, and reviewed and that adequate resources are available.

\section{ii. Initiating a quality risk management process}

It shouldinclude the systematic processes designed to coordinate, facilitate and improve science-based decision making with respect to risk. The possible steps used to initiate and plan a quality risk management process might include the following:

a. It should define the problem or risk question, including pertinent assumptions identifying the potential for risk

b. Assemble background information or data on the potential hazard, harm or human health impact relevant to the risk assessment.

c. Identify a leader and critical resources.

d. It should specify a timeline, deliverables, and appropriate level of decision making for therisk management process.

\section{iii. Risk assessment ${ }^{7}$}

The Risk assessment consists of the identification of hazards and the analysis and evaluation of risks associated with exposure to those hazards.

Quality risk assessments start with a welldefined problem description or risk question is well defined, an appropriate risk management tool and the types of information that will address the risk question will be more easily identifiable.

In clearly defining the risk for risk assessment purposes, three fundamental questions are often helpful:

1. What might be wrong?

2. What is the possibilityit will go wrong?

3. What are the consequences (severity)?

\section{iv. Risk identification}

It is astandardized use of information to identify hazards referring to the risk. Report can include historical data, theoretical analysis, and the concerns of stakeholders. Risk identification addresses the "what might go wrong?" question, including identifying the possible consequences. These provide the basis for further steps in the quality risk management process.

\section{v. Risk analysis}

Theconsideration of the risk associated with the identified hazards is risk analysis. It is the qualitative or quantitative process of linking the possibility of occurrence and severity of harms, in some risk management tool. The ability to detect the harm is also importantin the estimation of risk.

\section{vi. Risk evaluation}

It analyzes the identified and analyzed risk against given risk criteria.

The risk evaluations consider the strength of evidence for all three of the fundamental questions.

\section{Different steps involved in the risk assessment are ${ }^{8,9}$}

1. Collect and organize the information
a) Gathering relevant information, identifying assumptions.
b) Tools can be used to categorize the information.
c) Define the limits of the QRM exercise.

\section{Formulate the Risk Question}

It is the starting point of the QRM exercise, high level statement outlining the issue \& purpose for conducting the QRM exercise including risk factors, the scope of the issue and any related limits or constraints.

\section{Choose Tool different tools include}

a) Basic risk management facilitation methods (flowcharts, check sheets etc.)

b) Failure Mode Effects Analysis and Failure Mode Effects and Criticality Analysis.

c) Fault Tree Analysis.

d) Hazard Analysis and Critical Control Points.

e) Hazard \& Operability Analysis.

f) Preliminary Hazard Analysis.

g) Risk Ranking \& Filtering.

h) Supporting statistical tools.

\section{Identify Risks Factors and Related} Hazards

A hazard is a failure that could cause potential damageto the patient. Once the hazard isidentified, they can then beclassify into one of five areas: Operator, Environment, System, Reagents, or Specimen. This class will make it easier to later identify types of controls necessary to reduce unwanted risk. 
5. Define the Risk Components and Scales $^{14}$

RISK = PRIORITY * DETECTABILITY * SEVERITY

Where,

Severity- Criticality of the product.

Priority- Complexity of the site (multiproduct).

Detection - Audit history.

\section{Evaluate the risk for each hazard}

This is the step where you decide how repeatedly that failure will occur.

\section{Determine acceptability of risks}

Once the risks are designate, the next step is to look at severity and probability of harm to determine whether the risks are acceptable.
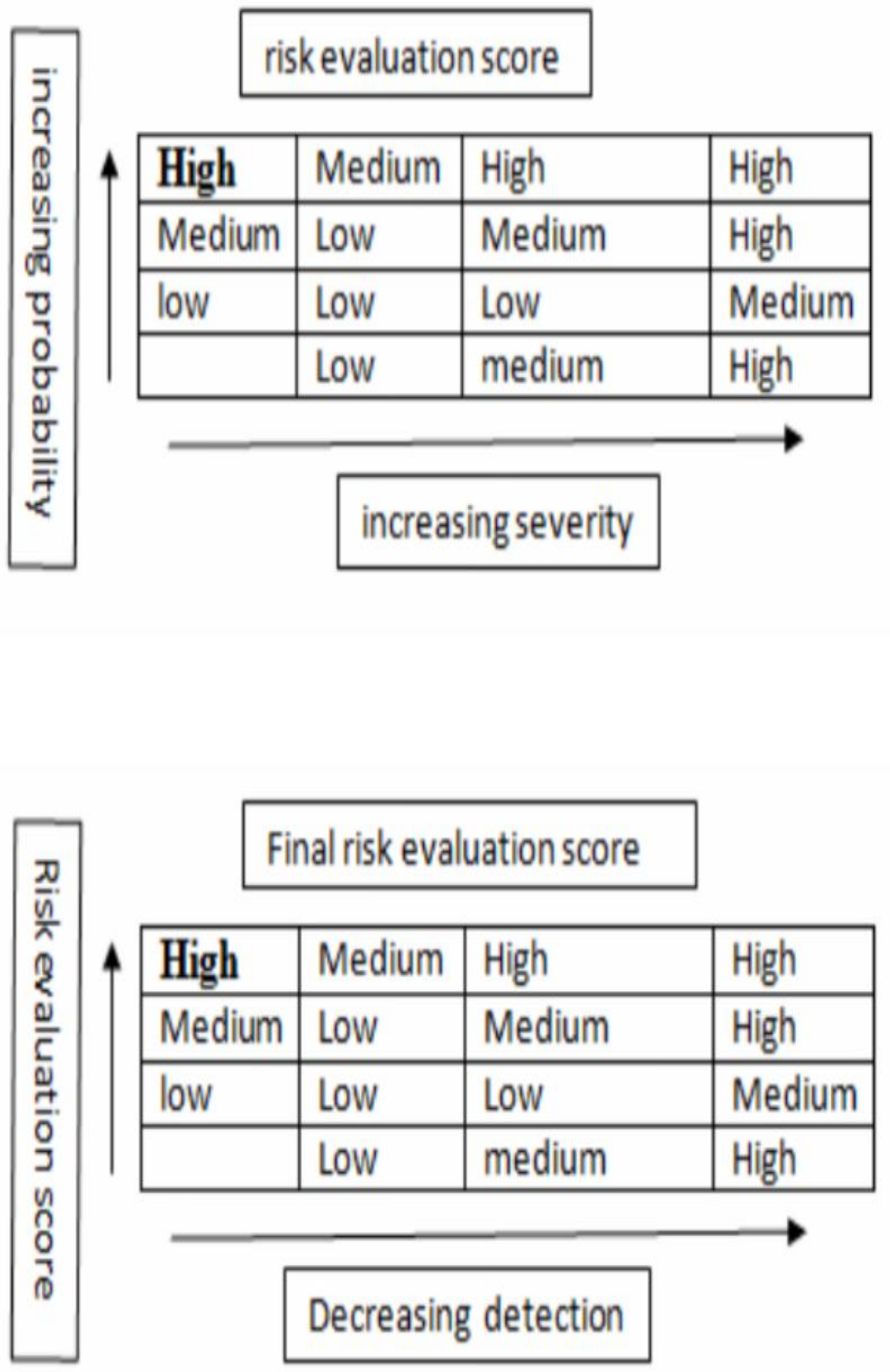

\section{Determine Action Threshold}


A level or value above which an action will take place and below which it will not.

\section{Apply the tool ${ }^{10}$}

a) Analyze the detailed risks and quantify those risks using the scales for severity, probability and detection to provide a risk score.

b) Conclude what actions are required based on the threshold for action.

\section{Risk control ${ }^{11}$}

The risk control includes decision making to reduce and/or accept risks. Theintentions of risk control are to reduce the risk to an acceptable level. Thevalue of effort used for risk control should be proportional to the significance of the risk.

The risk control might focus on the following questions

1. Is the risk above an acceptable level?

2. What are actions that might be taken to reduce or eliminate risks?

3. What are the appropriate balance among benefits, risks and resources?

4. Are new risks introduced as a result of the identified risks being controlled?

Risk management methodology ${ }^{10,11}$

It also includes some other factors like;

a. Risk MAP Tools

b. Failure Mode Effects Analysis (FMEA)

c. Failure Mode Effects and Criticality Analysis (FMECA)

d. Fault Tree Analysis (FTA)

e. Hazard Analysis and Critical Control Points (HACCP)

f. Hazard Operability Analysis (HAZOPA)

g. Preliminary Hazard Analysis (PHA)

h. Risk Ranking and Filtering

i. Supporting statistical Tool

Risk Map Tools ${ }^{7}$

Depending on your drug's specific issue(s), a variety of Risk MAP tools can be used to adequately minimize patient risk in the least burdensome way. These tools include:

a. Targeted education and outreach campaigns to health care practitioners and patients

b. Patient and physician agreement and consent processes

c. Tracking requirements for physicians, pharmacists and patients

d. Reminder systems, processes or forms

e. Systems and processes to track or limit drug distribution

f. The systems and processes to verify patient eligibility and compliance g. The real-world epidemiological safety studies by using databases, patient registries, surveys or other methods.

When is a risk map needed?

a) To expand health benefits while minimizing potential drug risks, sponsors are responsible for determining when Risk Maps are appropriate.

b) To do so, it is important to weigh the results of the pre-approval risk assessment, gauge the preventability of potential adverse events and consider the possibility of beneficial health outcomes.

c) For example, a Risk MAP could be implemented to minimize teratogenic drug exposures, enhance safeguards for addictive drugs or provide drug administration training for products with non-standard handling requirements.

Failure Mode Effect Analysis (FMEA) ${ }^{14,15}$

FMEA depends on product and process understanding. These methodically break down the analysis of complex processes into manageable steps. It provides assessment of potential failure modes for processes and their likely effect on product performance. These can be applied to equipment and facilities and might be used to analyze a manufacturing operation and its effect on product or process. Thesetools are further advanced with studying criticality of the consequences and providing clear indication of situation. The objective terminology and other details can vary according to type (e.g. operation FMEA, Design FMEA, Health FEMA etc.), the basic methodology is similar for all.

\section{Advantages of FMEA}

These are some advantage of performing FMEA analysis include higher reliability, better quality, increased safety and its contribution towards cost saving includes decreased development time and reduced waste and nonvalue added operations. The cost benefitlinked with FMEA are usually expected to come from the ability to identify failure modes earlier in the process, when they are less expensive to address. Financial advantages are also derived from the design improvements that FMEA is expected to facilitate, including decreased warranty costs, increased sales via enhanced customer satisfaction, etc. These provide a learning tool for new engineers and meets customer requirement and/or to comply with Safety and Quality requirements, such as ISO 9001, QS 
9000, ISO/TS 16949, Six Sigma, FDA Good Manufacturing Practices (GMPs), Process Safety Management Act (PSM) Ideally, FMEA is best done in conjunction with or soon after PHA efforts. Results can be used to identify high susceptibility elements and to guide resource deployment for best benefit. An FMEAcanbe done any time inthe system lifetime, from initial design forward.

Example of in- service Detection scale is given in Table 1

\begin{tabular}{|c|c|l|}
\hline Rank & $\begin{array}{c}\text { Likelihood of } \\
\text { Detection }\end{array}$ & $\begin{array}{c}\text { Criteria: } \\
\text { Likelihood of In-service Detection by Design Control }\end{array}$ \\
\hline $\mathbf{1 0}$ & $\begin{array}{c}\text { Ubsolute } \\
\text { Very Remote }\end{array}$ & Failure mode/cause are not detectable in-service \\
\hline $\mathbf{9}$ & Remote & $\begin{array}{l}\text { Failure mode/cause is possibly detected during offline } \\
\text { unplanned testing or inspection }\end{array}$ \\
\hline $\mathbf{8}$ & Verflure mode/cause is most likely detected during \\
\hline $\mathbf{7}$ & Low & $\begin{array}{l}\text { Failure mode/cause is possibly detected by offline } \\
\text { planned periodic testing or monitoring }\end{array}$ \\
\hline $\mathbf{6}$ & $\begin{array}{l}\text { Failure mode/cause is most likely detected by offline } \\
\text { planned periodic testing or monitoring }\end{array}$ \\
\hline $\mathbf{5}$ & Moderate & $\begin{array}{l}\text { Failure mode/cause is possibly detected by online } \\
\text { planned periodic testing or monitoring }\end{array}$ \\
\hline $\mathbf{4}$ & Very High & $\begin{array}{l}\text { Failure mode/cause is most likely detected by online } \\
\text { planned periodic testing or monitoring }\end{array}$ \\
\hline $\mathbf{3}$ & $\begin{array}{l}\text { Failure mode/cause is possibly detected by online } \\
\text { automatic continuous testing or monitoring } \\
\text { automatic continuous testing or monitoring }\end{array}$ \\
\hline $\mathbf{2}$ & Almost Certain & $\begin{array}{l}\text { Failure mode/cause is detected by online automatic } \\
\text { continuous testing or monitoring }\end{array}$ \\
\hline $\mathbf{1}$ & &
\end{tabular}

Failure Mode Effect and Critical Analysis (FMECA) ${ }^{3}$

The FMEA can be continued with an investigation of the degree of severity of the consequences, their respective probabilities of occurrence, and their detectability, thereby becoming a Failure Mode, Effects, and Criticality Analysis (FMECA; see IEC 60812). In organization for such an analysis to be performed, the product or process specifications should be established.these FMECA can identify places where additional preventive actions might be appropriate to minimize risks.

\section{Potential area to be used}

The FMECA application mostly uses in the pharmaceutical industry.it shouldbe utilized for failures and risks associated with manufacturing processes; but, it is not limited to this application. The basic output of an FMECA is a relative risk "score" for each failure mode, further which is used to rank the modes on a relative risk basis.

Fault Tree Analysis (FTA) ${ }^{16}$

These FTA mechanism or tool (see IEC 61025 ) is an approach that assumes failure of the functionality of a product or process. These methodevaluates system (or subsystem) failures one at a time but can combine multiple causes of failure by identifying causal chains. These results are represented in the form of a tree of fault modes. At the each level in the tree, combinations of fault modes are described with logical operators (AND, OR, etc.). FTA relies on the experts' process understanding to identify spontaneous factors.

\section{Potential area to be used}

The FTA can be used to establish the pathway to the root cause of the failure. These FTA can be used to investigate complaints or deviations in order to fully understand their root cause 
and to ensure that intended improvement will fully decision the issue and not lead to other issues (i.e. solve one problem yet cause a different problem). The FTA is an effective tool for evaluating how multiple factors affect a given issue. The amount of an FTA includes a visual representation of failure modes. It is beneficial for both in risk assessment and in developing monitoring program.

\section{Hazard Analysis and Critical control Points (HACCP) $^{17}$}

HACCP is a systematic, proactive, and preventive tool for assuring product quality, reliability, and safety (see WHO Technical Report Series No. 908, 2003, Annex 7). This is a structured way that applies technical and scientific principles to analyze, prevent, and control the risk or adverse consequence of hazard due to the design, development, production, and use of products.

HACCP consists of the following seven steps

a. These conduct a hazard analysis and identify preventive measures for each step of the process.

b. It determines the critical control points.

c. The establish critical limits.

d. These establish a system to monitor the critical control points.

e. These establish the corrective action to be taken when monitoring indicates that the critical control points are not in a state of control.

f. The establish system to verify that the HACCP system is working effectively

g. It establish a record-keeping system.

\section{- Investigation Parameters}

\begin{tabular}{|c|c|}
\hline Parameters & Causes \\
\hline Method & $\begin{array}{l}\text { A deviation caused by method or procedure not yielding the specified result, including those due to inadequate } \\
\text { equipment or procedure validation/qualification (equipment or procedures found inadequate or unsuitable for its } \\
\text { intended use), inadequate test method validation, or the establishment of specifications without adequate supporting } \\
\text { data. }\end{array}$ \\
\hline Operator & $\begin{array}{l}\text { A deviation caused by an error made by a Company employee or caused by insufficient training. } \\
\text { Operator Action } \\
\text {-Inattention to Detail } \\
\text {-Verbal or Written Communication Problem } \\
\text { - Operator Monitoring Multiple Processes } \\
\text { Operator Training: } \\
\text {-Not Trained on Procedure } \\
\text { - Not Trained on Current Version of Procedure } \\
\text {-Insufficient Practice or Experience } \\
\text {-Inadequate Content in Training }\end{array}$ \\
\hline Equipment & $\begin{array}{l}\text { A deviation caused by equipment, system or utility failure. } \\
\text { Equipment Failure } \\
\text {-Calibration Not Current } \\
\text {-Multiple Work Order(s) Addressing Same Issue Didn't Correct Problem } \\
\text { - Preventive Maintenance Not Current } \\
\text {-Out of Tolerance } \\
\text {-Equipment Not Operated According to Validated Procedure } \\
\text {-Defective Part } \\
\text {-Improper Part } \\
\text {-No IQ/OQ or Inadequate IQ/OQ } \\
\text {-Electrical Power Failure or Surge } \\
\text {-Computer system failure }\end{array}$ \\
\hline Environment & $\begin{array}{l}\text { A deviation caused by an air, surface, or water monitoring result (including HVAC operating specifications) that } \\
\text { exceeds alert or actions levels. }\end{array}$ \\
\hline Administrative & $\begin{array}{l}\text { Management System } \\
\text {-Inadequate Administrative Control } \\
\text {-Work Organization / Planning Deficiency } \\
\text { - Inadequate Supervision } \\
\text {-Improper Resource Allocation } \\
\text {-Information Not Adequately Defined, Disseminated or Enforced }\end{array}$ \\
\hline Other & Where the cause cannot be determined or more appropriately belongs in separate category not listed. \\
\hline
\end{tabular}


Quality risk management investigation ${ }^{4,1}$

\section{- Investigation Flow Sheet}

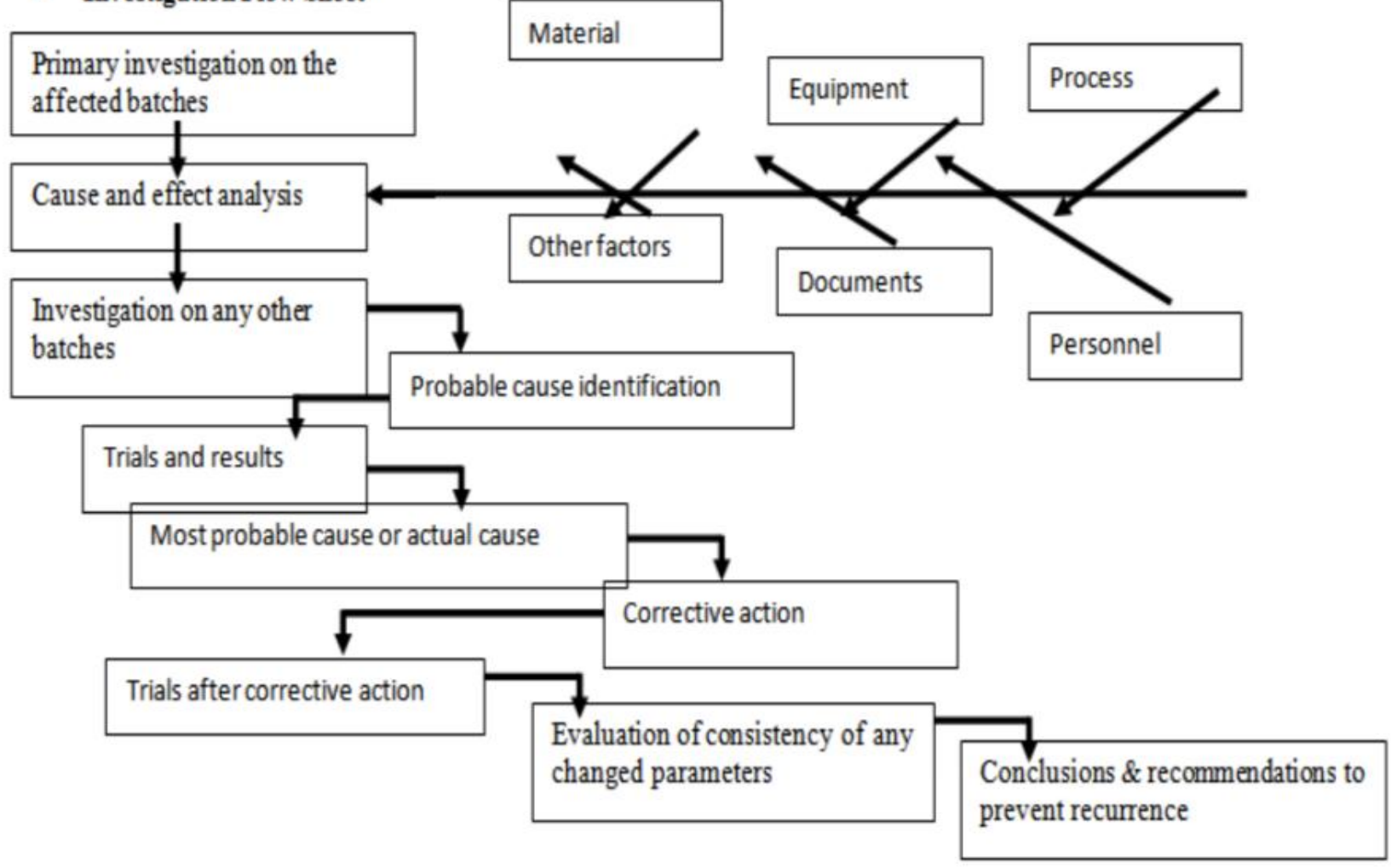

\section{CONCLUSION}

The Quality risk management process consists of four major components: risk assessment, risk control, risk review, and risk communication. All four components are essential. All the above methods and tools should address the mentioned four basic components. The team selection and method selection are also plays an important role in the risk management process, so care should be taken while collection or selection of risk management team and method. The FMEA is the favoredmethods for risk management in the pharmaceutical industry as FMEA analysis include higher reliability, better quality, increased safety and its contribution towards cost saving which includes decreased development time and reduced waste and non-value added activities.

\section{REFERENCES}

1. Joymalya Bhattacharya. A review article on Quality risk managementunderstanding and control the risk in pharmaceutical manufacturing industry. IJPSI. 2015;4:29.

2. Vijaya Kumar Reddy V, Vishal Gupta N, Raghunandan HV and Nitin Kashyap U. A review article on Quality risk management in pharmaceutical company. IJPR. 2014;6(3)908-914.

3. Prashant Kumar Katiyar and Jill Shukla B. A review article on risk analysis and risk management in pharmaceutical industry. IJPWR. 2010;1.

4. Guidance for industry. Q9 Quality Risk Management by US department of Health and Human Services, Food and drug Administration, Center for Drug and Evaluation Research. 2006.

5. Risk management - Vocabulary Guidelines for use in standards. 2002;28

6. WHO Guideline on Quality Risk Management A draft guidance. 2010.

7. Risk assessment and quality control by Max Williams. MPA. 2012.

8. Risk assessment and quality control by Max Williams. MPA. 2012.

9. Quality Risk Management- the pharmaceutical experience ann'omahony. 2011.

10. Kelvin C. Pharmaceutical engineering. GAMP 5. A Quality Risk Management Approach. 2008;28(3).

11. Risk Management: Guidelines and Best Practices Missouri Information Technology Advisory Board Project Management 
Committee Risk Management

Subcommittee. 2003.

12. Prashant Kumar Katiyar. International journal of pharma world research (an international quarterly pharmaceutical research journal) risk analysis and risk management in pharmaceutical industry. 2010.

13. Risk Management Vocabulary. Guidelines for Use in Standards. International organization for standardization. 2002.
14. Analysis techniques for system reliabilityProcedure for failure mode and effects analysis (FMEA). ICH Q9 Pharmaceutical Development. 2006.

15. Failure Mode and Effect Analysis. FMEA from theory to execution. Stamatis $\mathrm{DH}$. 2nd Edition. 2003.

16. Fault Tree Analysis made easy. 2005;1.5.

17. WHO Technical Report Series No. 908, 2003, Application of Hazard Analysis and Critical Control Point (HACCP) methodology to pharmaceuticals. 